\title{
Kalp Hızı Değişkenliği, Müteakip Gece Uyku Parametreleri ve Kortizol Uyanma Yanıtı ile İlişkili Değildi
}

\section{Heart Rate Variability was not Associated with Subsequent Night Sleep Parameters and Cortisol Awakening Response}

\author{
Cihat UCAR ${ }^{1}{ }^{\mathbb{D}}$, Tuba ÖZGÖÇER ${ }^{2} \mathbb{D}$, Sedat YILDIZ ${ }^{3}(\mathbb{D})$
}

\author{
1 Adıyaman Üniversitesi Tıp Fakültesi, Fizyoloji Anabilim Dalı, Adıyaman \\ 2 Harran Üniversitesi Tıp Fakültesi, Fizyoloji Anabilim Dalı, Şanlıurfa \\ 3 İnönü Üniversitesi Tıp Fakültesi, Fizyoloji Anabilim Dalı, Malatya
}

Öz.

Amaç: Uyku bozukluğu ve uyku düzeninin değişmesi hipotalamus-hipofiz-adrenal aksı (HPA) ve otonom sinir sistemini (OSS) etkilediği bildirilmiştir. Ancak gün içerisindeki otonom sinir sistemi aktivitesinin gece uykusuna ve bir sonraki gün HPA aksına etkisi bilinmemektedir. Bu nedenle, mevcut çalışmanın amacı, OSS aktivitesinin belirteci olan kalp hızı değişkenliğinin (KHD), gece uyku parametreleri ve bir sonraki gün HPA aksının belirteci olan kortizol uyanma yanıtına (KUY) olan etkisini incelemekti.

Materyal ve Metod: Bu çalışmada 48 sağlıkı Tıp Fakültesi öğrencilerinden KHD belirlemek için 5 dakikalık elektrokardiyografi (EKG) kaydı alındı. Takip eden gece normal uyku düzenlerinde uyumaları sağlandı. Uyku verilerini elde etmek için uyku ölçekleri dolduruldu (Karolinska uyku günlüğü ve ölçeği). KUY ölçümü için sabah uyandıktan $0,15,30$ ve 60 dakika sonra tükürük örnekleri toplandı. Tükürük örneklerinde kortizol konsantrasyonu enzim immunoassay yöntemiyle belirlendi. Korelasyonlar Spearman Rho ile bakıldı. $\mathrm{P}<0.05$ değerleri anlamlı kabul edildi.

Bulgular: Katılımcıların çoğunda (\%80) zaman bağımlı değişimlerin normal sınıllar içerisindeydi ve bu kişiler uyku bozukluğu yaşamamışlardı. Gün içerisinde elde edilen KHD'nin zaman ve frekans bağımlı parametrelerinin, takip eden gün içerisindeki uyku parametreleri (uyanma ve uyku süresi, uyku bozukluğu, uyanma problemleri) ve KUY (ortalama, eğri altında kalan alan) ile bir korelasyon bulunmadı ( $p>0.05$ ).

Sonuç: Bu çalışmanın sonuçları gösteriyor ki; OSS aktivitesi üzerinde derin etkileri olmayan koşullar altında ne uyku parametrelerinin ne de ertesi sabah kortizol yanıtlarının KHD'den etkilenmediğini göstermektedir. Buna ek olarak, kaliteli bir gece uykusu hem önceki günlerin otonom baskılarının olası etkilerini hem de ertesi sabahın kortizol tepkilerini dengeleyebilir.

Anahtar Kelimeler: Uyku, Kortizol, Kalp Hızı Değişkenliği

\section{Sorumlu Yazar I \\ Corresponding Author}

\section{Dr. Cihat UCAR \\ Adıyaman Üniversitesi Tıp Fakültesi \\ Fizyoloji Anabilim Dalı \\ 02000, Adıyaman, TÜRKIYE}

e-mail: ucarcht@gmail.com

Posta kodu:

TIf: 05416936444

Geliş tarihi / Received:

26.03.2020

Kabul tarihi / Accepted:

10.07.2020

DOI: $10.35440 /$ hutfd. 709479

Bu çalışma Cihat UÇAR'ın Doktora Tezinden üretilmiştir.
Background: Changes in sleep duration and sleep disturbance have been reported to affect hypothalamicpituitary-adrenal axis (HPA) and the autonomic nervous system (ANS) activities. However, the effect of ANS activity on sleep parameters and HPA activity in the subsequent night and morning is not known. The aim of the current study, was, therefore, to assess the effects of heart rate varibility (HRV) on subsequent night sleep parameters and cortisol awakening response (CAR).

Materials and Methods: Electrocardiographic recordings were carried out for 5 min for determination of HRV in healty medical students $(n=48)$. They were allowed to sleep in their normal routines in following night. Sleep diaries were filled for sleep parameters (Karolinska Sleep Diary and Questionnaire). Salivary samples were taken at $0,15,30$ - and 60-min post-awakening for measurement of CAR. Cortisol concentrations were measured in the salivary samples by enzyme immunoassay. Correlations were carried out by Spearman Rho. $p<0.05$ values were considered significant.

Results: The majority of the participants (80\%) had time-domain variables within the normal range and they did not have sleep disturbances. Time- and frequency-domain parameters of HRV during the morning did not correlate with sleep parameters (time, duration, disturbed sleep, awakening problems) or CAR (mean, area under the curve) in the next day ( $p>0.05)$.

Conclusion: The results of the current study suggest that, under the conditions which do not have profound effects on ANS activity, neither sleep parameters nor the next morning cortisol responses are affected by HRV. Additionally, a quality night sleep might counterbalance both the possible effects of previous days autonomic pressures and the next morning's cortisol responses.

Key words: Sleep, Cortisol, Heart rate variability 


\section{Giriş}

Yaşantımızın modernleşmesiyle birlikte sık sık kesintiye uğrayan ve süresi kısıtlanan uyku, birçok insan için yaygın görülen bir problemdir (1). Bu problemler arasında sabah erken uyanmak, uykuya dalmakta zorluk çekmek ve uyku süresinin azlığı bulunmaktadır (2). Ülkemizde, uykusuzluk semptomlarının genel prevalansı yaşa bağıı olarak \% 9.813.9 aralığında bulunmaktadır (3). Uyku bozukluğu ve uykusuzluk, obezite, diyabet, kardivasküler hastalıklar ve depresyon riskinin artmasıyla ilişkilidir (4). Uyku süresinin azalması ve uyku yoksunluğu ana nöroendokrin stres sistemlerinin, yani otonomik sinir sistemin (OSS) ve hipotalamo-hipofiz adrenal (HPA) aksın aktivitesinde geçici artışlarla ilişkili bir durumdur (5).

HPA aksının uyarılmasıyla son ürün olarak salgılanan kortizol 24 saat sirkadiyen ritim göstermektedir. Bu kortizol ritmi, uykudan uyanmanın ilk 30-45 dakikasında keskin bir artış göstermektedir ve bu artışa "kortizol uyanma yanıtı (KUY)" adı verilmektedir (6). Illk olarak 1990'ların başında tarif edilen KUY, HPA eksen aktivitesinin güvenilir bir ölçütü olarak kabul edilir (7). Bununla birlikte KUY, uyku parametreleri ile yakından ilişkilidir (5). Otonom sinir siseminin aktivitesini belirlemek için kullanılan en yaygın yöntem, non-invazif bir şekilde belirlenebilen kalp hızı değişkenliği$\operatorname{dir}(\mathrm{KHD}, \mathrm{HRV}=$ heart rate variability). KHD, normal kalp atımları arasındaki sürenin varyasyonunun hesaplanmasına dayalıdır. Bu amaçla en az 5 dakikalık süre ile Elektrokardiyografi (EKG) kaydı yapılır ve bu 5 dakikalık süre içindeki kalp atımları süresinin varyasyonu hesaplanır. KHD, fizyolojik olarak gün içerisinde sirkadiyen bir ritim göstererek geceleri artarken gündüzleri azalır (8). Stres belirteci olarak KHD kullanılabilir. KHD, zaman ve frekans bağımlı olmak üzere iki şekilde ifade edilir (9);

1. Zaman bağımlı analizler için;

- $\quad S D N N$, ms: Normal kalp atımları (R-R) aralarındaki sürelerin standart sapmasıdır.

- RMSSD, ms: Normal kalp atım aralıkları arasındaki farkların karelerinin toplamının ortalamasının karekökü

- pNN50, \%: Ardışık kalp atımları arasında 50 milisaniyeden fazla fark olanların yüzdesi

2. Frekans bağımlı analizler için;

- HF: yüksek frekans, $0.16-0.4 \mathrm{~Hz}$ arasındaki frekansları ifade eder. Parasempatik aktiviteyi yansıtır.

- LF: Düşük frekans, 0.04-0.15 arasındaki frekansları ifade eder. Sempatik aktiviteyi yansıtır.

- LF/HF: Bu oran sempato-vagal aktiviteyi yansitır. Artması sempatik aktivite artışını gösterir.

- TP: toplam güç, tüm kalp atımları arasındaki sürenin varyasyonudur.

Stres sistemleri ile uyku arasında çift yönlü ilişki bulunmaktadır (10). Kısa süreli uykunun, strese neden olduğu bildirilmiştir (11). HPA aksı, günlük yaşamda stresli olayların yanı sıra dinlenme ve günlük aktivitere de cevap verir ve metabolik, bilişsel ve psikiyatrik bozukluklarla açıkça ilişkilidir (12). Öte yandan, sağlıkı insanlarda duygusal ve bilişsel uyarılma uyku döngüsünü yöneten normal sirkadiyen ve homeostatik süreçleri de etkileyebilir. Uyku problemlerinin altındaki temel mekanizmanın, stresli olayların ve predispozan faktörlerin bir sonucu olarak aşırı uyarılmaya bağlı olabileceği bildirilmiştir (13).

Uyku süresi ve KUY arasındaki ilişkiyi inceleyen çalışmalar bulunmaktadır fakat uyku süresi-KUY ve KHD arasındaki ilişkiyi birlikte inceleyen çalışma bulunmamaktadır. Uyku süresi ve KUY ile ilgili çalışmaların sonuçlarında farklııklar bulunmaktadır. Örneğin, kısa uyku süresi olan kişilerde sabah kortizol uyanma yanıının artıı̆ı $(14,15)$, ancak diğer çalışmalarda uyku süresi ile KUY arasında bir ilişkinin olmadığı rapor edilmiştir $(16,17)$. Uyku ve KHD arasındaki ilişki incelendiğinde, uykunun fizyolojik olarak tüm süresi boyunca ve uyku bozukluğu olanlarda KHD'nin farklı olabileceği bildirilmiştir (18).

Çalışmamızın amacı, genç bireylerde gün içerisinde sempatik veya parasempatik aktivite artışının gece uykusuna ve sabah KUY' a etkisi incelemekti. Mevcut çalışma, KHD'deki değişikliklerin uyku parametrelerine ve kortizol yanitına olabilecek olası etkileri inceleyen literatürdeki ilk verileri oluşturacaktır.

\section{Materyal ve Metod}

Çalışmanın gerçekleştirimesi için Malatya Klinik Araştırmalar Etik Kurulundan 27.05.2015 tarihinde Protokol \#2015/45 ile izin alınmıştır. Çalışmaya katılan bireyler bilimsel farkındalığa sahip olan İnönü Üniversitesi Tıp Fakültesi öğrencileri seçilmiştir. Katılımcılar, yaş ortalaması 21 olan (18-24) öğrencilerden ( $n=48$, Erkek=32, Kadın=16), ilaç kullanmayan ve kronik hastalığı olmayan ve sigara içmeyenlerden oluşturuldu. Kadın katılımcılar menstrüel siklusun luteal fazında bulunuyorlardı. Katılımcılar ile deneyden bir gün öncesinde bire bir görüşüldü, deneyin uygulanması anlatılı ve cep telefon numaraları alındı. Uyulacak prosedür ise yazılı olarak her katılımcıya verildi (Şekil 1). Çalışmaya başlandığı gün KHD analizlerinin yapılması için Neurosoft (EKG) cihazı ve Poly-spectrum yazilım programı kullanılarak 5 dakikalık EKG kaydı alınmıştır. Alınan tüm EKG kayıtları öğleden önce alınmıştır. Bu amaçla katılımcıların bir sedye üzerinde rahat bir şekilde uzanır pozisyonda olmaları sağlanmıştır. Bireylere normal nefes alıp vermeleri, herhangi bir şekilde hareket etmeden ve konuşmadan uzanır pozisyonda kalmaları için bilgi verilmiştir. EKG kaydı için sadece kol-bacak derivasyonları kullanılmıştır. Tükürük toplama tüpleri $(1.5 \mathrm{ml}$ ependorf tüp) ve doldurmaları gerekli olan anketler her katılımcıya verilmiştir. EKG kaydının yapıldığı akşam standart günlük yaşamlarına devam etmeleri gerektiği, uyuma saatine en az 4 saat kala spor yapmamaları, TV izlememeleri, yemek ve tatı gibi gıdaların tüketilmemesi gerektiği söylendi. Katıımcılara alıştıkları şekilde uyumaları gerektiği belirtilerek 
herhangi bir uyku parametresine müdahale edilmedi (son 1 aylık uyku düzenindeki gibi uyudular). Sabah uyanan katlııcı ilk tükürük örneğini (0. dakika) verdikten sonra kendilerine verilen çalar saati 15 veya 30 dakikaya ayarlayıp diğer tükürük örnekleri $(0,15,30$ ve 60 . dakikalarda tükürük örneklerinin alınması) kontrollü bir şekilde toplanması sağlandı. Tükürük örnekleri pasif akış yöntemi kullanılarak alındı (5). Tükürük örneklerini verdiği bir saatlik süre boyunca evde (veya yurt) bulunulması ve aşırı fiziksel aktiviteden kaçınılması gerektiği belirtilmiştir. Çalışmanın tüm safhalarında bilgilendirme mesajları atıldı ve protokole uyamadıklarını belirtenler deneyden çıkarıldı. Katılımcılar topladıkları tükürük örneklerini aynı gün içinde getirmeleri istendi, tükürük örneği toplama aşaması bittikten sonra geç gelecek olanlar için tükürük örneklerini $+4 \mathrm{C}$ saklanması gerektiği belirtildi. Toplanan tükürük örneklerinde kortizol ölçümü ELISA (Enzyme-Linked ImmunoSorbent Assay) yöntemiyle yapılmıştır (19). Elde edilen, tükürük kortizol değerleri ile oluşturulan eğrinin altında kalan tüm alan (Area under curve ground-AUC ${ }_{g}$ ) ve artış gösterilen alan (Area under curve increase-AUC ${ }_{i}$ ) hesaplandı (7). Uyku ölçeklerinden Karolinska Uyku Günlüğü ve Karolinska Uyku Ölçeği (aylık) uygulandı (16). Uyku ölçeklerinde puanlandırma yapıldı. İstatistiksel analiz için tüm verilere normal dağılım analizi (normality plots with tests) uygulanmıştır. Veriler normal dağılım göstermediği için korelasyonlar Spearman Rho katsayısı ile hesaplandı. Tüm veriler ortanca ile beraber minumum ve maximum değerleri ile özetlendi. $\mathrm{P}<0.05$ değerleri anlamlı olarak kabul edildi. Analizlerde IBM SPSS 22.0 Statistics programı kullanıldı.

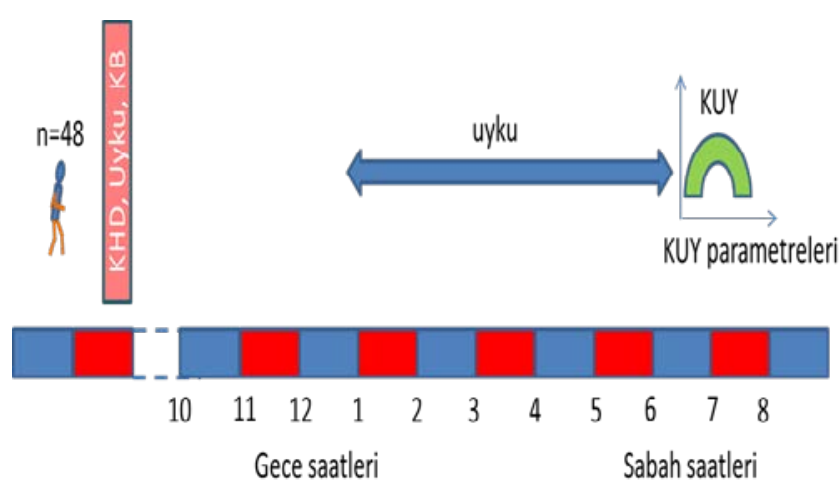

Şekil 1. Çalışma Prosedürü

\section{Bulgular}

Çalışmadan elde edilen veriler arasında anlamlı korelasyona rastlanmamışı ır $(p>0.05)$ ancak bazı parametrelerde orta seviyede korelasyonlar mevcuttur $(p<0.05)$. Çalışmaya katılan bireylerden elde edilen tükürük kortizol değerleri Tablo 1' de gösterilmiştir. Kortizol değerlerinden, uyandıktan 60 dakika sonra ölçülen kortizol değeri ile kalp hızı değişkenliği parametresi olan LF değerinin yüzdelik parametresi (\% LF) arasında anlamlı orta seviyede bir pozitif ilişki tespit edilmiştir ( $r: 0.278, p<0.05$ )
Tablo 1. Sabah ölçülen genel otonom aktiviteye müteakip sabah kortizol konsantrasyonları ve hesaplanan AUC değerleri (Tüm değerler ortanca-en küçük ve en büyük değer olarak verilmiştir).

\begin{tabular}{ll}
\hline Değişkenler & $\begin{array}{c}\text { Genel Otonom Aktivite-Uyku-KUY } \\
\text { (Ortanca-en küçük değer-en büyük değer) }\end{array}$ \\
\hline Kortizol (ng/ml) & \\
Uyandığında (0. dk) & $30.58(3.14-5008)$ \\
15. Dakika & $27.73(3.07-4198)$ \\
30. Dakika & $33.76(11.38-1544)$ \\
60. Dakika & $54.17(8.28-1075)$ \\
AUCg & $2920(663-79710)$ \\
AUCi & $1135(97-76075)$ \\
\hline
\end{tabular}

$\overline{A U C}_{g}$; area under curve ground-eğri altında kalan alan-tümü, $\boldsymbol{A U C _ { i }}$; area under curve increase-eğri altında kalan alan-artış

Tablo 2. KUY öncesi sabah ölçülen KHD parametreleri (Tüm değerler ortanca-en küçük ve en büyük değer olarak verilmiştir).

\begin{tabular}{|c|c|}
\hline Değişkenler & $\begin{array}{r}\text { Genel Otono } \\
\text { (Ortanca-en küçi }\end{array}$ \\
\hline $\begin{array}{l}\text { KHD Parametreleri } \\
\text { Kalp Hızı (atım/dk) }\end{array}$ & $75.85(51.2-98.9)$ \\
\hline SDNN (ms) & $57(28-116)$ \\
\hline RMSSD (ms) & $44.5(20-140)$ \\
\hline pNN50 (\%) & $17.1(0.6-70.6)$ \\
\hline $\mathrm{TP}\left(\mathrm{ms}^{2}\right)$ & $2733(759-12421)$ \\
\hline $\operatorname{VLF}\left(\mathrm{ms}^{2}\right)$ & $828(143-5916)$ \\
\hline $\mathrm{LF}\left(\mathrm{ms}^{2}\right)$ & $823(203-6974)$ \\
\hline $\mathrm{HF}\left(\mathrm{ms}^{2}\right)$ & 783 (168-5911) \\
\hline LF/HF oranı & $1.34(0.17-4.39)$ \\
\hline$\%$ VLF & $31.8(6.7-62.6)$ \\
\hline$\%$ LF & $34.2(10.1-60.3)$ \\
\hline$\% \mathrm{HF}$ & $27(12.8-72)$ \\
\hline
\end{tabular}

SDNN; Normal kalp atılımları arası sürenin standart sapması, RMSSD; Normal kalp atımları arasındaki farkların karelerinin toplamının ortalamasının karekökü, pNN50; Ardışık kalp atımları arasında 50 milisaniyeden fazla fark olanların yüzdesi, TP; toplam güç, VLF; çok düşük frekans, LF; düşük frekans, HF; yüksek frekans, KUY; kortizol uyanma yanıtı, KHD; kalp hızı değişkenliği

Tablo 3. Sabah ölçülen genel otonom aktivite sonrası gece uyku parametrelerinin (günlük).

\begin{tabular}{ll}
\hline Değişkenler & $\begin{array}{l}\text { Genel Otonom Aktivite-Uyku-KUY } \\
\text { (Ortanca-en küçük değer-en büyük değer) }\end{array}$ \\
\hline Karolinska Uyku Günlüğüu & \\
Bozulmuş Uyku & $1.25(0.75-5)$ \\
Uyanma Sorunları & $2.45(1-4.3)$ \\
Uyku Süresi (saat) & $5.6(3-9)$ \\
\hline
\end{tabular}

Tablo 4. Çalışmaya katılan bireylerin son bir aylık uyku parametleri (puanlandırma)

\begin{tabular}{ll} 
Değişkenler & $\begin{array}{l}\text { Genel Otonom Aktivite-Uyku-KUY } \\
\text { (Ortanca-en küçük değer-en büyük de- } \\
\text { ğer) }\end{array}$ \\
\hline Karolinska Uyku Ölçeği & \\
(son 4 hafta) & \\
Uyku Bozukluğu & $4(1.5-5)$ \\
Uyanma Sorunları & $2.5(1-5)$ \\
Uyku Kalitesi & $3(1-4)$ \\
\hline
\end{tabular}

Çalışmaya katılan bireylerde sabah ölçülen KHD parametreleri Tablo 2' de, günlük uyku parametreleri Tablo 3' de ve aylık uyku parametreleri Tablo 4' de sunulmuştur. Uyku bozukluğu ve uyanma sorunları ile \% LF arasında orta seviyede pozitif ilişki mevcuttur (sırasıyla r: $0.284 p<0.05$, r: $0.330 p<0.05$ ). Uyanma sorunları (günlük ve aylık) ile uyandıktan 60 dakika sonra ölçülen kortizol arasında orta seviyede pozitif ilişki mevcuttur (r: $0.319 p<0.05)$. Uyku sü- 
resi ile uyanır uyanmaz (0. dakika) ölçülen kortizol arasında ise orta seviyede negatif ilişki tespit edilmiştir ( $r$ : $0.292 p<0.05)$.

\section{Tartışma}

Mevcut çalışmada, sabah kaydedilen KHD ile müteakip akşam uyku parametreleri ve sonraki sabah KUY arasındaki ilişkiler incelenmiş ve bu bağlamda konuya özgün bir yaklaşım getirmiştir. Oysaki daha önce yapılan diğer çalışmalarda, bozulmuş uyku düzeninin veya kalitesinin KHD ve KUY üzerine etkilerini incelemiştir (20-22). Dolayısıyla bozulmuş uyku düzeninin KHD ve KUY'u etkilemesi olasılığı beklenen bir homeostatik yanıt iken (20), mevcut çalışma, KHD'deki değişikliklerin uyku parametrelerini ve kortizol yanıtını etkilemiş olmasına ilişkin literatürdeki ilk verileri oluşturmuştur.

$\mathrm{KHD}$ verileri genel olarak incelendiğinde, SDNN değeri, katılımcıların çoğunda (\% 80) 50 ms'nin üzeri olarak kabul edilen normal değerler arasında tespit edilmiştir. Literatürde, SDNN değeri 50 ms'nin altında bulunan kişilerin kardiyovasküler hastalıklar yönünden $\% 400$ oranında daha riskli bulundukları bildirildiğinden (23), mevcut çalışmada yaklaşık 10 kişinin (\% 20) riskli grupta bulunduğu sonucuna varılabilir. Bu yönüyle değerlendirildiğinde, genç bir öğrenci popülasyonda bu değer yüksek bulunmuş olup buna yönelik yeni çalışmalar yapılarak tedbirler alınması gerekliliği belirmiştir. Frekans bağımlı parametreler (LF, HF ve VLF) ile uyku ve KUY verileri arasında bir ilişki tespit edilememiştir. Diğer çalışmalarda uyku parametreleri ile uyku anında ölçülen LF arasında pozitif ilişkiler tespit edilmiştir. Öte yandan, uykunun fazlarının KHD parametrelerini etkilediği ve bu bağlamda rüya görülen REM uykusunun sempatik sinir sistemi aktivitesinin artışıyla ilişkili olduğu belirtildiğinden $(24,25)$, bu dönemde uyku parametreleri ile KHD'nin sempatik parametreleri arasında ilişkiler tespit edilmesi beklenen bir olasilıktır. Nitekim REM uykusu ile LF arasında pozitif ilişki belirlemişlerdir $(24,25)$. Oysa mevcut çalışmanın hedefi uykudan önceki gün içerisindeki KHD parametrelerinin uyku üzerine etkilerini belirlemek olduğundan konuya farklı bir yaklaşım açısı getirmiştir. Bu bağlamda, frekans bağımlı parametrelerin \% oranının her birey için ayrı ayrı olarak belirlendiği \% LF, \% HF ve \% VLF değerleri içinde, sempatik aktivitenin göreceli etkinliğini gösteren \% LF ile bozulmuş uyku arasında pozitif ilişkiler belirlenmiş olması, önceki gün yüksek sempatik aktivite gösteren bireylerde uykunun bozulabileceğine ilişkin bir belirti olarak değerlendirilmiştir.

Mevcut çalışmada, \% LF ile uyandıktan sonra 60. dakika kortizol arasında pozitif ilişki bulunmuştur. Bir gün önce sempatik aktivitesi yüksek olan kişilerde o gün gece uyku bozukluğunun artığı ve sabah uyandıktan bir saat sonraki kortizol seviyesinin yükseldiği düşünülebilir. Benzer şekilde, Izawa ve arkadaşları (26) tarafından 20 genç katıIımcı üzerinde yapılan çalışmada, uyanmadan önce ve uyandıktan sonra sempatik aktivitenin artışının kortizol uyanma yanıtını etkilediğini bildirilmiş̧ir.

Mevcut çalışmada, uyku süresi ile uyanır uyanmaz (0. dakika) kortizol konsantrasyonu arasında negatif ilişki tespit edilmiş olması, kısa uyku süresinin kortizol uyanma yanıtının yüksek bir konsantrasyondan başlamasına yol açtığı şeklinde yorumlanabilir. Benzer şekilde, uyku süresinin azalmasının uyanır uyanmaz ölçülen kortizol konsantrasyonunu artırdığı bildirilmiştir $(15,27)$. Ayrıca, önceki gün veya son 4 hafta içerisinde uyanma sorunları yaşayan bireylerde uyandıktan 60 dakika sonraki kortizol konsantrasyonu ile AUC yüksek bulunmuş ve bu durum kişinin yeterince dinlenemediği şeklinde yorumlanmıştır. Dolayısıyla yeterince dinlenemeyen bireylerde, artmış kortizol uyanma yanıtının homeostatik olarak günlük aktiviteler için bir direnç kazandığı sonucuna varılmıştır. Konuyla ilgili yapılan bir başka çalışma incelendiğinde (16), günlük uyanma sorunları ve uyku bozukluğu ile sabah uyandıktan sonraki tükürük kortizolü arasında herhangi bir ilişki bulunmamıştır. Bu sonuç mevcut çalışmanın sonuçları ile uyuşmamaktadır. Her iki çalışma karşılaştırıldığında, mevcut çalışmanın yaş aralığı dar olan (18-24) ve konunun bilincinde olan katılımcılar üzerinde yapıldığı, buna karşın Hansen vd. (16)'nin ise yaş aralı̆̆ geniş olan (19-66) bir popülasyon üzerinde yapıldığı anlaşılmaktadır. Yaşlanmayla birlikte uyku süresi ve kalitesinde ve ayrıca kortizol hormonun salgılanmasında çeşitli sorunlar oluşacağı aşikârdır. Yine Hansen vd. (16)'de popülasyonun \% 70'i kadınlardan oluşmuşken mevcut çalışmada bu oran \% 33'tür. Bayanlarda döngüsel olayların (28) ve menapozun (29) tükürük kortizolü üzerine etkileri bildirilmiş olduğundan, mevcut çalışmanın verilerinin daha güvenilir olduğu değerlendirilmiştir. Çalışmayla ile elde edilen veriler değerlendirildiğinde aşağıdaki sonuçlara varılabilir:

1. Gündüz saatlerinde artan sempatik aktivite, müteakip gecede uyku bozukluklarına yol açmıştır.

2. Gündüz saatlerinde artan sempatik aktivite, müteakip sabah saatlerinde uyanmayla birlikte oluşan kortizol yanıtını artırmışıı.

3. Kısa süre uyku uyuyanlarda, kortizol uyanma yanıtı yüksek bir kortizol değeri ile başlamaktadır.

4. Uyanma sorunu yaşayan bireylerde kortizol uyanma yanıtı daha yüksek olmaktadır.

Dolayısıyla, KHD-Uyku-KUY arasında önemli etkileşimlerin bulunduğu tespit edilmiş ve uyku ile ilgili parametrelerin değerlendirilmesinde hem KHD'nin hem de KUY'un belirlenmesinin faydalı olacağı kanısına varımıştır.

Çalışmamızı sınırlandıran faktörlerde bulunmaktadır. Bunlardan bazıları şunlardır; EKG kayıtları gece boyunca yapılabilirdi ancak çalışmanın yapılabilirliği ve katılımcıların kabul etmesi yönünden sıkıntıları bulunmaktaydı. Katıımcllardan elde edilecek uyku parametreleri, uyku merkezinde uyutularak elde edilebilirdi ancak bu durumda katılımcı- 
larda farklı ortamda alet kabloları ile birlikte uyumak gerektireceğinden stres yaratabilir ve çalışmamızda istenilen sonucu gölgeleyebilirdi.

\section{Açıklamalar \\ Etik Onam: Malatya Klinik Araştırmalar Etik Kurulundan 27.05.2015 tarihinde Protokol \#2015/44 ile onay alınmıştır.}

Bu çalışma Inönü Üniversitesi Bilimsel Araştırma Projeleri ve Koordinasyon Birimi tarafından desteklenmiştir (Proje No: 2015/96)

\section{Kaynaklar}

1. Hillman DR, Lack LC. Public health implications of sleep loss: the community burden. Med J Aust. 2013;199(8): S7-S10.

2. Bonnet MH, Arand DL. We are chronically sleep deprived. Sleep. 1995;18(10):908-11.

3. Benbir G, Demir AU, Aksu M, Ardic S, Firat H, Itil O, et al. Prevalence of insomnia and its clinical correlates in a general population in Turkey. Psychiatry Clin Neurosci. 2015;69(9):543-52.

4. Van Cauter E, Spiegel K, Tasali E, Leproult R. Metabolic consequences of sleep and sleep loss. Sleep Med. 2008;9 (Suppl 1)(0 1):S23-S28.

5. Uçar C, Özgöçer T, Yildiz S. Late-night exercise affects the autonomic nervous system activity but not the hypothalamo-pituitary-adrenal axis in the next morning. J Sports Med Phys Fitness. 2018;58(1-2):57-65.

6. Ozgocer T, Ucar C, Yildiz S. Cortisol awakening response is blunted and pain perception is increased during menses in cyclic women. Psychoneuroendocrinology. 2017;77:158-64.

7. Pruessner JC, Kirschbaum C, Meinlschmid G, Hellhammer DH. Two formulas for computation of the area under the curve represent measures of total hormone concentration versus time-dependent change. Psychoneuroendocrinology. 2003;28(7):916-31.

8. Marques AH, Silverman MN, Sternberg EM. Evaluation of stress systems by applying noninvasive methodologies: measurements of neuroimmune biomarkers in the sweat, heart rate variability and salivary cortisol. Neuroimmunomodulation. 2010;17(3):205-8.

9. Shaffer F, McCraty R, Zerr CL. A healthy heart is not a metronome: an integrative review of the heart's anatomy and heart rate variability. Front Psychol. 2014;5:1040.

10. Tobaldini E, Nobili L, Strada S, Casali KR, Braghiroli A, Montano N. Heart rate variability in normal and pathological sleep. Front Physiol. 2013;4:294.

11. Meerlo $P$, Koehl $M$, van der Borght $K$, Turek FW. Sleep restriction alters the hypothalamic-pituitary-adrenal response to stress. J Neuroendocrinol. 2002;14(5):397-402.

12. Kinlein SA, Karatsoreos IN. The hypothalamic-pituitary-adrenal axis as a substrate for stress resilience: Interactions with the circadian clock. Front Neuroendocrinol. 2020;56:100819.

13. Akerstedt T. Psychosocial stress and impaired sleep. Scand J Work Environ Health. 2006;32(6):493-501.

14. Wüst S, Wolf J, Hellhammer DH, Federenko I, Schommer N, Kirschbaum $\mathrm{C}$. The cortisol awakening response - normal values and confounds. Noise Health. 2000;2(7):79-88.

15. Kumari M, Badrick E, Ferrie J, Perski A, Marmot M, Chandola T. Self-reported sleep duration and sleep disturbance are independently associated with cortisol secretion in the Whitehall II study. J Clin Endocrinol Metab. 2009;94(12):4801-9.

16. Hansen AM, Thomsen JF, Kaergaard A, Kolstad HA, Kaerlev L, Mors O, et al. Salivary cortisol and sleep problems among civil servants. Psychoneuroendocrinology. 2012;37: 1086-95.

17. Stalder T, Evans P, Hucklebridge F, Clow A. Associations between psychosocial state variables and the cortisol awakening response in a single case study. Psychoneuroendocrinology. 2010;35: 209-14.
18. Tsai HJ, Kuo TB, Lee GS, Yang CC. Efficacy of paced breathing for insomnia: enhances vagal activity and improves sleep quality. Psychophysiology. 2015;52(3):388-96.

19. Ozgocer T, Yildiz S, Uçar C. Development and validation of an enzyme-linked immunosorbent assay for detection of cortisol in human saliva. J Immunoassay Immunochem. 2017;38(2):147-64.

20. Michels N, Sioen I, Clays E, De Buyzere M, Ahrens W, Huybrechts I, et al. Children's heart rate variability as stress indicator: Association with reported stress and cortisol. Biol Psychol. 2013;94:433-40.

21. Bonnet MH, Arand DL. Sleepiness as measured by modified multiple sleep latency testing varies as a function of preceding activity. Sleep. 1998;21(5):477-83.

22. Dettoni JL, Consolim-Colombo FM, Drager LF, Rubira MC, Souza $\mathrm{SB}$, Irigoyen $\mathrm{MC}$, et al. Cardiovascular effects of partial sleep deprivation in healthy volunteers. J Appl Physiol. 2012;113(2):232-6.

23. Kleiger RE, Miller JP, Bigger JT Jr, Moss AJ. Decreased heart rate variability and its association with increased mortality after acute myocardial infarction. Am J Cardiol. 1987;59(4):256-62.

24. Dettenborn L, Rosenloecher F, Kirschbaum C. No effects of repeated forced wakings during three consecutive nights on morning cortisol awakening responses (CAR): a preliminary study. Psychoneuroendocrinology. 2007;32(8-10):915-21.

25. Crasset V, Mezzetti S, Antoine M, Linkowski P, Degaute JP, van de Borne P. Effects of aging and cardiac denervation on heart rate variability during sleep. Circulation. 2001;103(1):84-8.

26. Izawa S, Sugaya N, Yamamoto R, Ogawa N, Nomura S. The cortisol awakening response and autonomic nervous system activity during nocturnal and early morning periods. Neuro Endocrinol Lett. 2010;31(5):685-9.

27. Lemola S, Perkinson-Gloor N, Hagmann-von Arx P, Brand S, Holsboer-Trachsler E, Grob A, et al. Morning cortisol secretion in school-age children is related to the sleep pattern of the preceding night. Psychoneuroendocrinology. 2015;52:297-301.

28. Wolfram M, Bellingrath S, Kudielka BM. The cortisol awakening response (CAR) across the female menstrual cycle. Psychoneuroendocrinology. 2011;36(6):905-12.

29. Gomez-Santos C, Saura CB, Lucas JA, Castell P, Madrid JA, Garaulet M. Menopause status is associated with circadian- and sleeprelated alterations. Menopause. 2016;23(6): 682-90. 